\title{
Hypoxic Ventilatory Drive in Normal Man
}

\author{
John V. Weil, Edward Byrne-Quinn, Ingvar E. Sodal, W. Otto Friesex, \\ Brian UNDERhILl, Giles F. Filley, and Robert F. Grover
}

From the Department of Medicine and Webb Waring Institute, University c?: Colorado Medical Center, Denver, Colorado 80220

A B S T RACT A technique is described which permits the inscription of the ventilatory response to isocapnic hypoxia in man as a continuous curve relating alveolar oxygen tension and minute ventilation. The adjustment of ventilation to changes in alveolar oxygen tension is complete in 18-23 sec and this is sufficiently rapid to justify the use of a non-steady-state method. Changes in alveolar carbon dioxide tension are prevented by addition of carbon dioxide to the inspired gas. The resulting $\mathrm{V}_{\mathrm{E}}-\mathrm{PAO}_{2}$ curves are hyperbolic such that falling $\mathrm{PAO}_{2}$ produces only slight rises in $\mathrm{V}_{\mathrm{E}}$ until a critical $\mathrm{PAo}_{2}$ range of $50-60 \mathrm{~mm} \mathrm{Hg}$ is reached. With further fall in $\mathrm{PAO}_{2}, \mathrm{~V}_{\mathrm{E}}$ increases steeply and the slope of the curve approaches infinity at a tension of $30-40 \mathrm{~mm} \mathrm{Hg}$. For purposes of quantitation these curves are approximated by a simple hyperbolic function, the parameters of which are evaluated by a least squares fit of the data. The parameter $A$ denotes curve shape such that the higher the value of $A$, the greater the increase in ventilation for a given decrease in $\mathrm{PAO}_{2}$ and hence the greater the hypoxic drive. Curves are highly reproducible for each subject and curves from different subjects are similar. In 10 normal subjects at resting $\mathrm{PAco}_{2}$, $\mathrm{A}=180.2 \pm 14.5$ ( $\mathrm{SEM}$ ). When $\mathrm{PAco}_{2}$ is adjusted to levels $5 \mathrm{~mm} \mathrm{Hg}$ above and below control in six subjects $\mathrm{A}=453.4 \pm 103$ and $30.2 \pm 6.8$ respectively. These latter values differed significantly from control $(P<0.05)$. These changes in curve shape provide a clear graphic description of interaction between hypercapnic and hypoxic ventilatory stimuli. At normal $\mathrm{PAcO}_{2}$ the $\mathrm{V}_{\mathrm{E}}-\mathrm{PAO}_{2}$ curve has an inflection zone located over the same $\mathrm{P}_{2}$ range as the inflection in the oxygenhemoglobin dissociation curve. This indicated that ventilation might be a linear function of arterial oxygen saturation or content. Studies in four subjects have

This work presented in part at American Federation for Clinical Research Meeting, May 1969, Atlantic City, N. J., and the 12th Aspen Emphysema Conference, June 1969, Aspen, Colo.

Received for publication 16 October 1969 and in revised form 11 February 1970. demonstrated that ventilation is indeed related to arterial oxygen content in a linear fashion. These data suggest, but do not prove, that oxygen tension in chemoreceptor tissue as in part determined by circulatory oxygen delivery may be an important factor in controlling the ventilatory response to hypoxia.

\section{INTRODUCTION}

Acute changes in pulmonary ventilation are predominantly under the control of the carbon dioxide-hydrogen ion system. However, chronic adjustments of ventilation often appear to be dictated mainly by oxygen requirements of the organism. Adaptation of animals to high altitude, for example, is accompanied by increase in ventilation and substantial reduction in $\mathrm{PAco}_{2}$ (1). Similarly, evolution-related changes in ventilation which occurred during the emergence of aquatic animals from the water on to the land indicate that air breathing which greatly increased the availability of oxygen resulted in marked decreases in ventilation with tenfold increases in carbon dioxide tension (2). In both circumstances it would appear that chronic changes in ventilation were dictated primarily by hypoxic ventilatory drive while renal mechanisms maintained normal hydrogen ion concentration. There was little attempt to hold carbon dioxide tension at any particular level. In spite of its apparent importance in chronic adjustment of ventilation hypoxic ventilatory drive has not been commonly studied directly because it is technically difficult to measure. Hyperventilation induced by hypoxia produces hypocapnia and alkalosis and both are potent inhibitors of ventilation. Hence studies of the ventilatory response to simple administration of low oxygen gases describe a response which is a resultant of hypoxic stimulation and hypocapnic-alkalotic inhibition. For this reason ventilatory responses to hypoxia must be measured under conditions in which the usual changes in blood carbon dioxide tension and $\mathrm{pH}$ are prevented. The studies of Loeschke and Gertz (3), Cormack, Cun- 
ningham, and Gee (4), and Tenney, Remmers, and Mithoefer (5) utilized methods which permitted measurement of ventilatory responses to hypoxia at constant carbon dioxide tensions. Relatively few data points were obtained in each subject during these studies and there was little information concerning the precision with which carbon dioxide tension was controlled during hypoxia. More commonly, information concerning hypoxic respiratory drive is calculated from the change in slope of $\mathrm{P}_{\mathrm{CO}_{2}}$-ventilation lines done at different oxygen tensions $(6,7)$. However, this technique describes the ventilatory response to hypoxia as a single number, $\Delta \mathrm{V}_{40}$, and leaves the form of the ventilation- $\mathrm{PAO}_{2}$ relationship undescribed. Ventilatory responses to single breath administration of nitrogen have also been used for this purpose but neither the intensity of the stimulus nor completeness of response is well documented with this method. As a result no studies have been reported in which a large volume of data has been collected in a given individual at a single sitting. Hence considerable variation exists in the literature regarding both the mag- nitude and the exact nature of the ventilatory response to hypoxia in normal man.

The present study is concerned with the description of the ventilatory response to isocapneic hypoxia as a continuous curve relating minute ventilation and alveolar oxygen tension. These curves are hyperbolic and closely resemble the oxygen-hemoglobin dissociation curve. In contrast, the relationship between arterial oxygen content and minute ventilation is essentially linear.

\section{METHODS}

Subjects participating in the study were normal males between the ages of 22 and $45 \mathrm{yr}$. None were actively involved in formal athletics or formal physical conditioning programs and none were born at altitudes greater than a few hundred feet above sea level. All were long-term residents (1-20 yr) of Denver, Colo. (1600 m). All studies were done in the laboratories of the Webb-Waring Institute and the University of Colorado Medical Center in Denver. Each subject was informed of the purpose and details of the study and consent was obtained from all participants.

Details of the method are outlined in Fig. 1. The subject breathes through a respiratory valve (Hans Rudolph) from

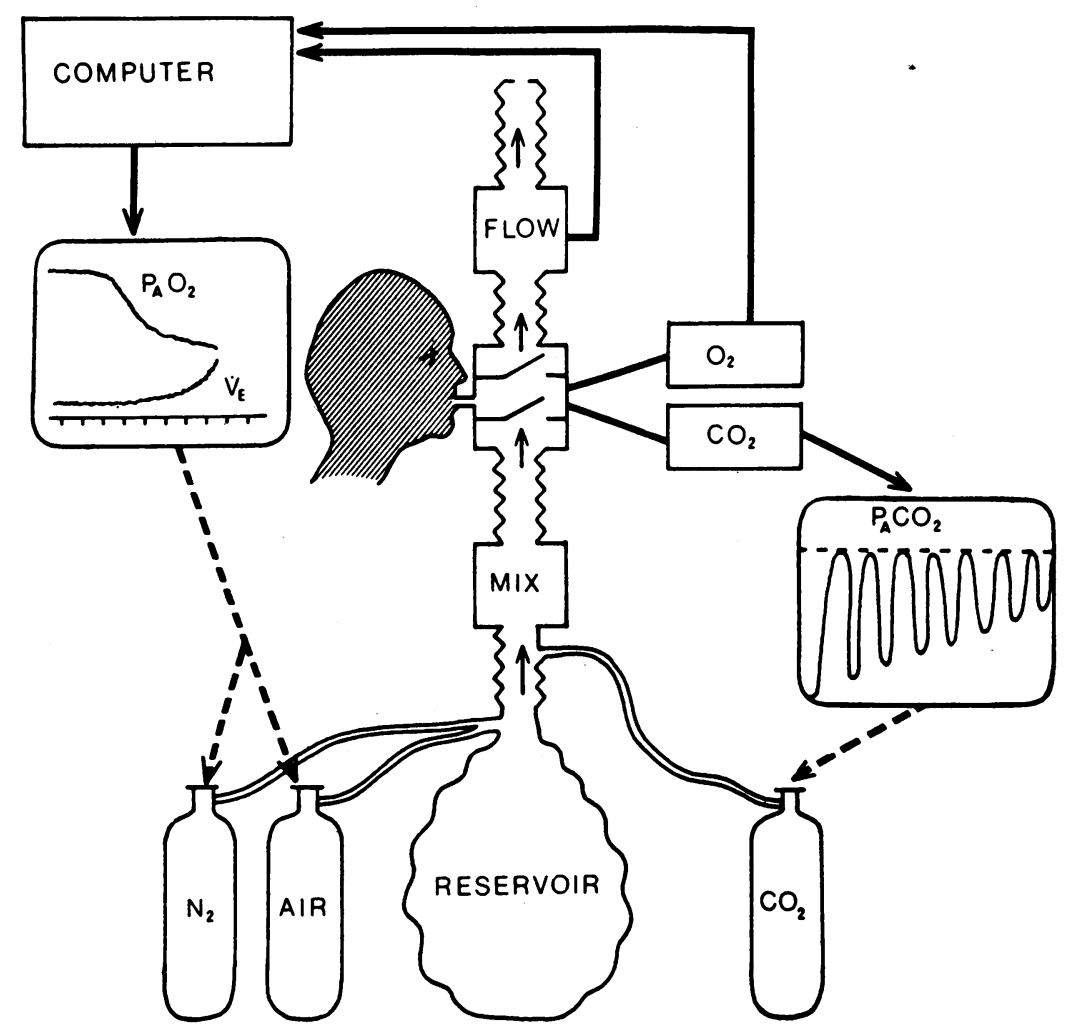

FIGURE 1 Outline of method used to induce progressive isocapnic hypoxia. Alveolar oxygen tension is computed from fuel cell oxygen analyzer signal and used to guide addition of nitrogen to inspired gas. Output of $\mathrm{CO}_{2}$ analyzer provides a guide to the addition of $\mathrm{CO}_{2}$ to inspired gas in amounts sufficient to prevent hypocapnia. 


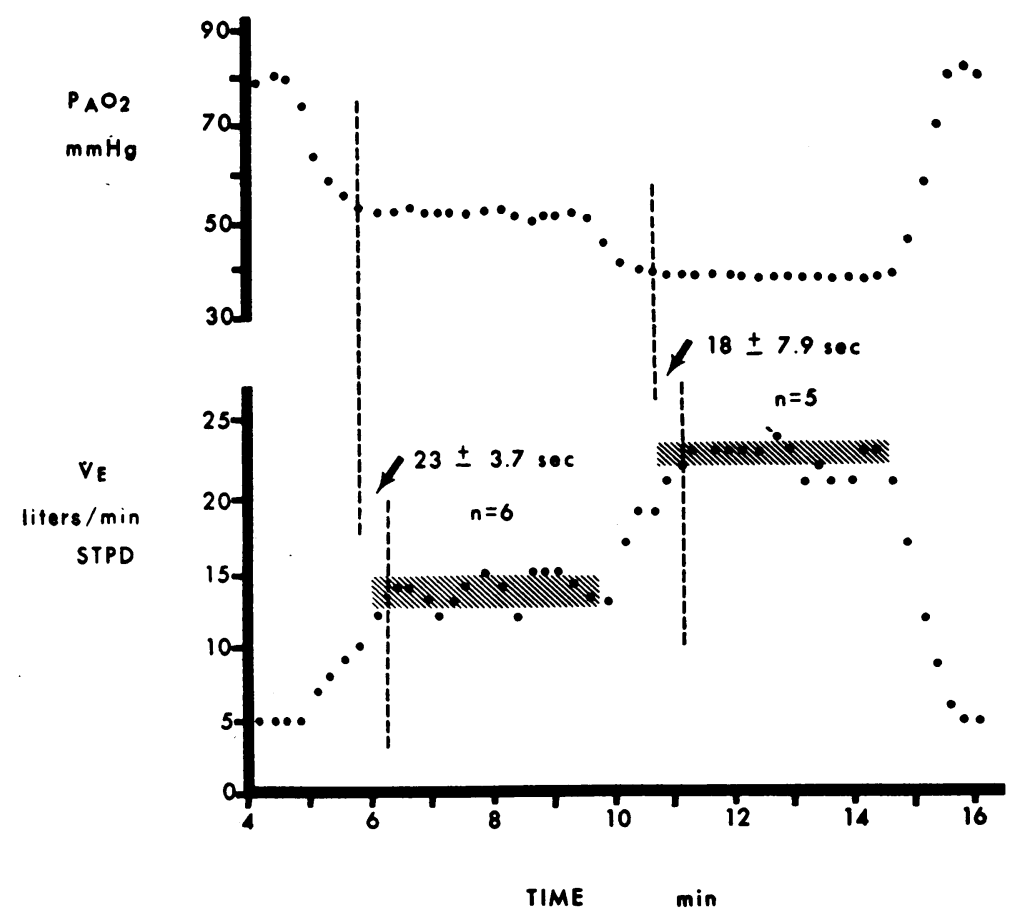

FIGURE 2 Kinetics of the ventilatory response to sudden introduction of two successive hypoxic gas mixtures. Alveolar $\mathrm{P}_{\mathrm{O}_{2}}$ and $\nabla \mathbf{E}$ are from a representative study while the numbers shown for phase lag are mean of six and five studies.

which gases are sampled by an infrared carbon dioxide analyzer (Beckman LB-1) and by a fuel cell, rapid oxygen analyzer. Design and performance of the latter instrument have been described elsewhere $(8,9)$. Output from the fuel cell $\mathrm{O}_{2}$ analyzer together with information from a pneumotachograph are fed into an on-line PDP-8 computer. These data emerge as nearly continuous, real time, oscilloscopic plots of end-tidal oxygen tension, carbon dioxide tension, and minute ventilation. The end-tidal oxygen plot is used as a guide to the manual addition of $100 \%$ nitrogen to the stream of inspiratory gas such as to produce a gradual fall in end-tidal tension from 120 to $40 \mathrm{~mm} \mathrm{Hg}$ over $15-20 \mathrm{~min}$. Output from the carbon dioxide analyzer is also displayed on an oscilloscope and this information is used during the study to guide the manual addition of $100 \%$ carbon dioxide to the inspired gas in amounts sufficient to prevent hypocapnia. This process is represented schematically in Fig. 1 by a rising inspired $\mathrm{CO}_{2}$ tension with constant end-tidal tension. Resting or control $\mathrm{PAco}_{2}$ was determined by measurement of end-tidal $\mathrm{P}_{\mathrm{CO}_{2}}$ during several brief periods of breathing room air through the circuit used in the study. On occasion $\mathrm{PAcO}_{2}$ was low initially and tended to increase slightly over several minutes, eventually stabilizing at a higher value. A $\mathrm{PACO}_{2}$ which remained stable during successive 3 - to 5 -min breathing periods was accepted as the control value.

In order to determine whether data collected in such nonsteady-state circumstances could be used in any meaningful fashion, a series of studies was conducted to examine the kinetics of ventilatory adjustment to square-wave hypoxic gas stimuli under isocapnic conditions. In each of six subjects breathing room air, an inspiratory gas mixture con- taining $10.27 \% \quad \mathrm{O}_{2}$ in $\mathrm{N}_{2}$ was suddently introduced for 5 min and constant end-tidal $\mathbf{P}_{\mathrm{CO}_{2}}$ was maintained as described above. After this $5 \mathrm{~min}$ period, a second gas containing $8.51 \% \quad \mathrm{O}_{2}$ in $\mathrm{N}_{2}$ was introduced for another $5 \mathrm{~min}$. At the end of this period the inspiratory gas was abruptly changed to room air (see Fig. 2). After the introduction of hypoxic gases rather long periods of up to $2 \mathrm{~min}$ were required to lower alveolar oxygen tension. However, the intervals between the time at which stabilization of alveolar $\mathrm{P}_{\mathrm{O}_{2}}$ occurred and the time at which the ventilation curve entered its $95 \%$ tolerance band were very short. For the room air to $10.27 \% \quad \mathrm{O}_{2}$ portion of the study, alveolar $\mathrm{P}_{\mathrm{O}_{2}}$ fell from $85 \pm 2.3$ ( $\mathrm{SEM}$ ) to $50.6 \pm 0.81 \mathrm{~mm} \mathrm{Hg}$ and the interval between stabilization of $\mathrm{P}_{\mathrm{O}_{2}}$ and stabilization of ventilation averaged $23 \pm 3.7 \mathrm{sec}$. The second phase of the study reduced $\mathrm{P}_{\mathrm{O}_{2}}$ from $50.6 \pm 0.81$ to $39.2 \pm 0.31$. In this case ventilation stabilized within $18 \pm 7.9 \mathrm{sec}$ of attainment of stable $\mathrm{O}_{2}$ tension. In the non-steady-state studies described above the rate of change of oxygen tension below $60 \mathrm{~mm} \mathrm{Hg}$ is $3.6 \mathrm{~mm} \mathrm{Hg} / \mathrm{min}$. Thus a $20 \mathrm{sec}$ delay interval represents a maximal effective $\mathrm{PAO}_{2}$ phase error of $1.2 \mathrm{~mm}$ $\mathrm{Hg}$ higher than actually observed at that time. It should be emphasized that these data were computed during sudden changes in $\mathrm{PAO}_{2}$ and hence represent more rigorous conditions than those actually pertaining during slowly progressive hypoxia. Thus the measured phase error represents the worst possible case and undoubtedly overestimates that encountered during the studies to be described.

In six subjects ventilation- $\mathrm{PAO}_{2}$ curves were measured following acutely sustained alterations in alveolar $\mathbf{P A c o}_{2}$. These curves were done at control $\mathrm{PACO}_{2}$, at $\mathrm{PAcO}_{2} 5 \mathrm{~mm} \mathrm{Hg}$ above control and at $\mathrm{PACO}_{2} 5 \mathrm{~mm} \mathrm{Hg}$ below control. Hypo- 
capnia was produced by voluntary hyperventilation sufficient to reduce the $\mathrm{PAco}_{2}$ to a level $5 \mathrm{~mm} \mathrm{Hg}$ below control. After this had been achieved voluntary hyperventilation was discontinued and induction of progressive hypoxia was begun. Hypercapnia was produced by progressive addition of carbon dioxide to the inspired gas until a $\mathrm{PAco}_{2} 5 \mathrm{~mm}$ $\mathrm{Hg}$ greater than control was achieved. This level was maintained throughout the hypoxic study.

Arterial blood studies. In four subjects the ventilatory response to progressive isocapnic hypoxia was measured in conjunction with arterial blood gases and $\mathrm{pH}$. After two complete $\mathrm{PAO}_{2}-\mathrm{VE}$ curves had been inscribed a Cournand needle was placed in either a radial or brachial artery. Progressive isocapnic hypoxia was induced as described above and $8-\mathrm{ml}$ arterial blood samples were taken over the first $20 \mathrm{sec}$ of each minute of the 15-20 min study. Samples were collected anaerobically in oiled, heparinized syringes and placed in ice. Within a few minutes $\mathrm{Pa}_{2}$, and $\mathrm{Paco}_{2}$ and $\mathrm{pH}$ were measured with appropriate electrodes (Radiometer Co., Copenhagen). Oxygen content and capacity were measured with a Van Slyke apparatus on each sample within $120 \mathrm{~min}$.

Accuracy of transducers. Our experience with analysis of oxygen using the fuel cell oxygen analyzer has been previously described (8). Currently, results with this device differ from Scholander data by 0.008 volume $\%$ with a standard deviation of 0.015 volume $\%$ over a range of $5-21 \% \mathrm{O}_{2}$. Ventilation is measured using a pneumotachograph. Because of the inherent alinearity of this instrument a calibration curve with two linear phases is employed: one for gas flows below, and one for flows in excess of 640 liters/min. The computer program is designed to apply two separate respective calibrations for flows in these two ranges. This corrects for turbulence errors and produces agreement to better than $5 \%$ with simultaneous volumes measured with a Tissot spirometer over the entire range encountered in these studies.

Computer program. The sampling rate of the on-line computer (PDP-8) is 50 samples per sec for all incoming analog signals. During the sampling interval $(20 \mathrm{msec})$ calculation of values for $\mathrm{PAO}_{2}, \mathrm{PAcO}_{2}$, and ventilation is completed. These data are displayed as real time output and are stored on magnetic disc for later transmission to a larger time-shared computer system (GE-400) for nonlinear least squares curve fitting.

\section{RESULTS}

Results of a typical study are shown in Fig. 3. This plot relating alveolar oxygen tension and ventilation is composed of points which represent the mean value for $\mathrm{PAo}_{2}$ and ventilation computed from three successive breaths..

In order to compare individual curves more conveniently we have employed a simple empirical equation relating ventilation and alveolar $\mathrm{P}_{\mathrm{O}_{2}}$ which constitutes a reasonably close description of these curves. Those values for the parameters of such an equation which produce an optimum least squares fit for a given curve provide quantitative information regarding the shape and position of that curve. We have tested several expressions and have found that an equation similar to one originally suggested by Lloyd, Jukes, and Cunningham (7) works as well as any for this purpose. The
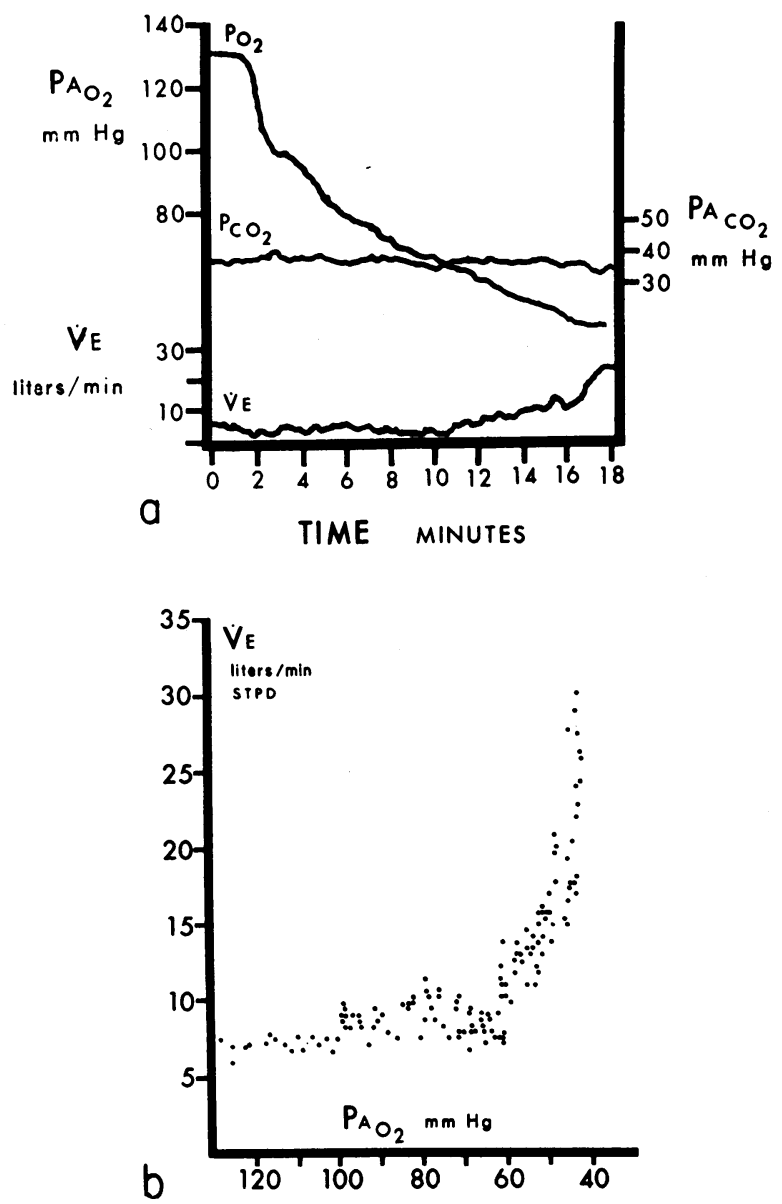

Figure 3 Ventilatory response to progressive isozapnic hypoxia in a typical normal subject. (a) Time course of ventilation, alveolar oxygen tension, and carbon dioxide tension. (b) Relationship between minute ventilation and alveolar oxygen tension in this same subject. Each point represents the mean value for oxygen tension and ventilation for three successive breaths.

equation relates ventilation and alveolar $\mathrm{P}_{0_{2}}$ as follows: $\mathrm{VE}_{\mathrm{E}}=\mathrm{V}_{\mathrm{E}}{ }^{0}+\mathrm{A} /\left(\mathrm{PAO}_{2}-32\right)$, where $\mathrm{V}_{\mathrm{E}}$ and $\mathrm{PAO}_{2}$ are minute ventilation in liters per minute STPD and alveolar $\mathrm{P}_{\mathrm{o}_{2}}$ in millimeters of mercury respectively. Parameter $\mathrm{VE}^{0}$ is the asymptote for ventilation obtained by extrapolation and parameter $A$ determines the shape of the curve such that the higher the value for $A$ the greater the hypoxic ventilatory drive. (see Fig. 4). The constant 32 represents the $\mathrm{PAO}_{2}$ at which the slope of the $\mathrm{VE}-\mathrm{PAo}_{2}$ curve approaches infinity and was obtained by extrapolation in 18 studies in six normal subjects. In practice the curve fitting procedure including evaluation of parameters is accomplished using a GE-400 computer programmed for a least squares fit using Marquardt's method (10). This equation yields curves which fit the observed data very closely over a wide range of 


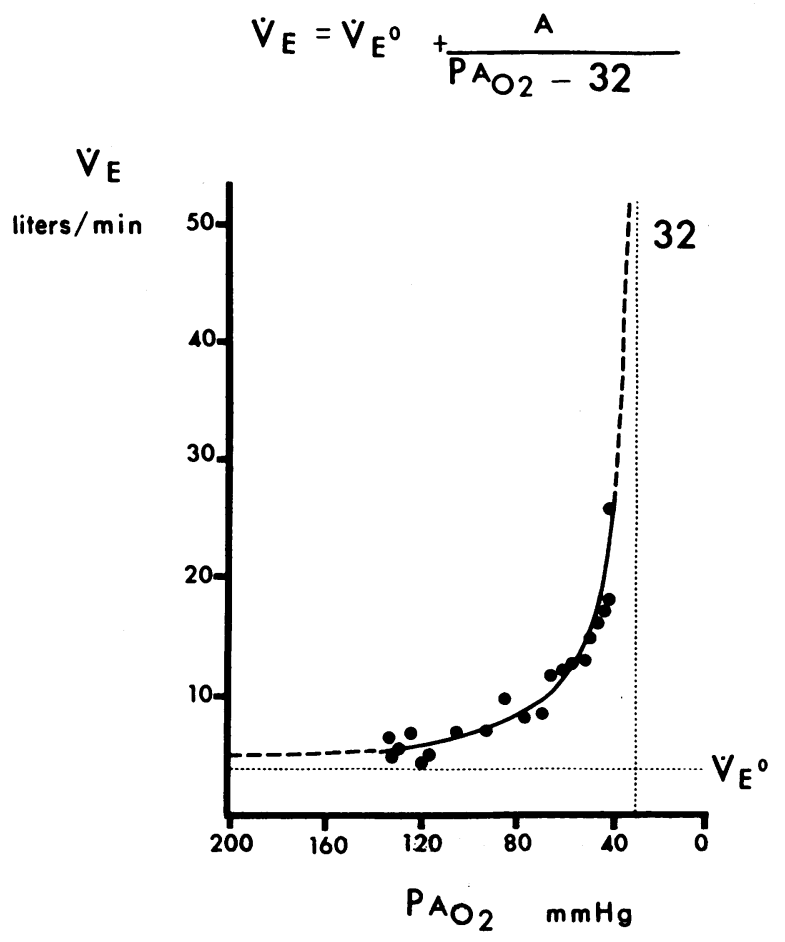

FIGURE 4 The curve resulting from a least squares fit to the equation shown above. The parameter $\nabla_{E^{0}}$ is the value for ventilation extrapolated to an infinitely great $\mathrm{PA}_{\mathrm{A}_{2}}$ while the parameter A describes curve shape. The data points shown were obtained by reduction of the original 150 points (Fig. $3 b$ ) to 20 points by taking serial means.

curve shapes (see Fig. 6). Analysis of variance of the regression revealed a very low error or residual contribution such that in all cases $P<0.005$ for regression and in most cases $P<0.0005$. The goodness of

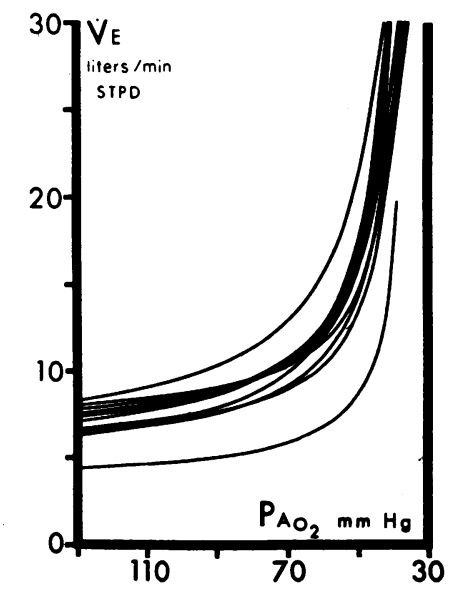

FIGURE 5 Alveolar oxygen tension-minute ventilation curves in 10 normal subjects. Curves are the result of nonlinear least squares fit as described in the text.

fit of the computed curves to the actual data may also be gauged by examination of residuals, that is the difference between the ventilation measured at a given $\mathrm{PAO}_{2}$ and that calculated from the fitted curve. In 20 studies for $\mathrm{PAO}_{2}=40-45 \mathrm{~mm} \mathrm{Hg}$ this residual difference for ventilation averaged $-0.49 \pm 0.37$ (SEM) liter/ min. For this $\mathrm{PAo}_{2}$ range ventilation averages about 25 liter/min so the observed residual error is about $2 \%$.

Curves in 10 normal subjects are shown in Fig. 5 and values for $A$ and $\nabla_{E^{0}}$ in Table $I$. The mean value for $A$ at control $\mathrm{PAco}_{2}$ was $180.2 \pm 14.5$ (SEM) and $V_{E^{0}}$ averaged $4.8 \pm 0.51 / \mathrm{min}$. In order to estimate the precision with which changes in $\mathrm{PAco}_{2}$ were prevented mean values for $\mathrm{PAco}_{2}$ during the "normoxic" phase of the study $\left(\mathrm{P}_{\mathrm{O}_{2}}>85 \mathrm{~mm} \mathrm{Hg}\right)$ were compared with mean $\mathrm{PAco}_{2}$

TABLE I

Hypoxic Ventilatory Drive in 10 Normal Subjects

\begin{tabular}{|c|c|c|c|c|c|c|c|c|c|}
\hline \multirow[b]{2}{*}{ Subject } & \multirow[b]{2}{*}{ Age } & \multirow[b]{2}{*}{$\mathrm{Ht}$} & \multirow[b]{2}{*}{$\mathbf{W t}$} & \multirow[b]{2}{*}{ BSA } & \multicolumn{2}{|c|}{$\mathrm{PACO}_{2}$} & \multirow[b]{2}{*}{$\mathbf{A}$} & \multirow[b]{2}{*}{$\mathrm{VE}^{0}$} & \multirow{2}{*}{$\begin{array}{c}\text { No. } \\
\text { of } \\
\text { studies }\end{array}$} \\
\hline & & & & & Normoxia & Hypoxia & & & \\
\hline & $y r$ & $\mathrm{~cm}$ & $k g$ & $m^{2}$ & \multicolumn{2}{|c|}{$m m \mathrm{Hg}$} & & & \\
\hline 1. E. B.-Q. & 33 & 175 & 74.1 & 1.90 & 36.1 & 35.0 & 159.7 & 5.3 & 7 \\
\hline 2. V. C. & 22 & 181 & 68.6 & 1.87 & 41.9 & 41.0 & 99.5 & 4.4 & 3 \\
\hline 3. R. F. G. & 45 & 180 & 71.0 & 1.91 & 39.0 & 38.7 & 194.8 & 4.9 & 4 \\
\hline 4. M. J. & 22 & 180 & 88.6 & 2.09 & 32.2 & 31.9 & 169.6 & 5.0 & 2 \\
\hline 5. R. McG. & 26 & 185 & 93.9 & 2.19 & 39.1 & 37.8 & 170.1 & 6.2 & 3 \\
\hline 6. M. R. & 23 & 180 & 105.5 & 2.25 & 33.1 & 33.8 & 176.9 & 4.8 & 2 \\
\hline 7. I. E. S. & 35 & 182 & 67.7 & 1.88 & 32.9 & 32.7 & 142.5 & 5.8 & 5 \\
\hline 8. B. U. & 30 & 182 & 67.7 & 1.88 & 38.2 & 38.2 & 272.2 & 4.3 & 4 \\
\hline 9. J. V. W. & 34 & 175 & 75.5 & 1.91 & 36.8 & 35.6 & 217.2 & 2.6 & 7 \\
\hline 10. R. Y. & 22 & 179 & 88.6 & 2.08 & 36.1 & 34.8 & 199.8 & 5.0 & 2 \\
\hline Mean & & & & & 36.5 & 36.0 & 180.2 & 4.8 & \\
\hline SEM & & & & & 1.0 & 0.9 & 14.5 & 0.3 & \\
\hline
\end{tabular}




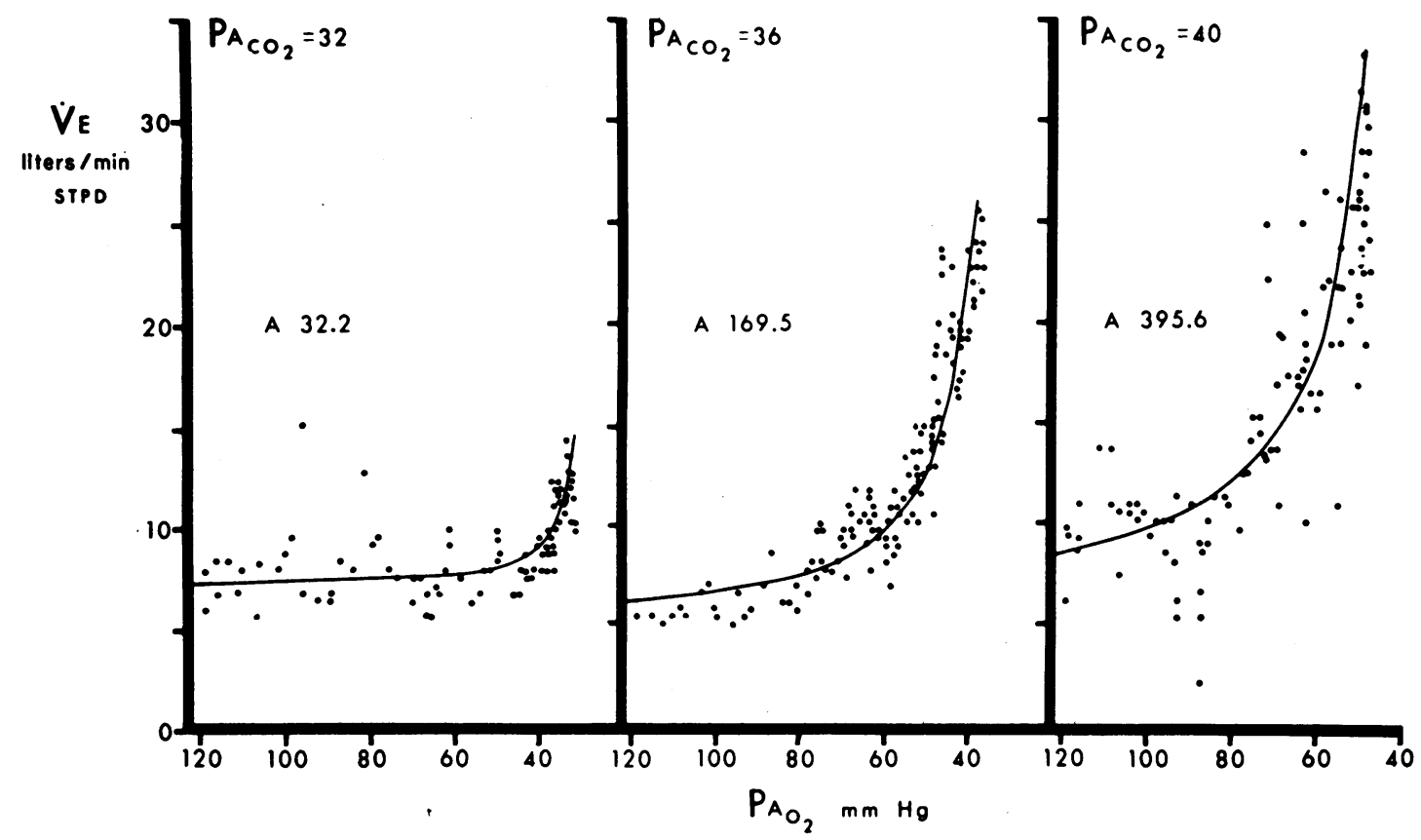

FIGURE 6 Influence of acute sustained alteration in alveolar carbon dioxide tension on ventilatory response to hypoxia in a typical subject (E. B.-Q.). Observed data points are shown in relation to the computed curve for each study.

during the "hypoxic" phase $\left(\mathrm{PAo}_{2}<85 \mathrm{~mm} \mathrm{Hg}\right)$. The difference between these two values for 10 studies averaged $-0.89 \mathrm{~mm} \mathrm{Hg}$ with a standard deviation of 1.09 $\mathrm{mm} \mathrm{Hg}$.

Effects of acute alterations in alveolar carbon dioxide tension. Acute reduction of alveolar $\mathrm{Pco}_{2}$ by voluntary hyperventilation resulted in an attenuation of the ventilatory response to hypoxia in all six subjects. This was reflected in a consistently decreased value for $A$, the shape-determining parameter, in these subjects. Con- versely acute hypercapnia accentuated the response of ventilation to hypoxia and increased the value for $A$ in all subjects (Table II). A representative series of studies at three $\mathrm{PAco}_{2}$ levels in a single subject is shown (Fig. 6). These changes were found to be statistically significant by analysis of variance $(P<0.05)$.

Arterial blood studies. In four subjects arterial blood samples were collected at $1 \mathrm{~min}$ intervals during progressive hypoxia (Table III). Results of a representative study are plotted against time in Fig. 7. Mean ventila-

TABLE II

The Effect of Changes in $\mathrm{PACO}_{2}$ on Hypoxic Ventilatory Drive in Normal Man

\begin{tabular}{|c|c|c|c|c|c|c|c|c|c|}
\hline \multirow{2}{*}{$\begin{array}{c}\text { Subject } \\
n=6\end{array}$} & \multicolumn{3}{|c|}{ Hypocapnia } & \multicolumn{3}{|c|}{ Normocapnia } & \multicolumn{3}{|c|}{ Hypercapnia } \\
\hline & $\mathrm{PACO}_{2}$ & $\mathbf{A}$ & $\mathrm{VE}^{0}$ & $\mathrm{PACO}_{2}$ & $\mathbf{A}$ & $\mathrm{VE}^{0}$ & $\mathrm{PACO}_{2}$ & A & $\mathrm{VE}^{0}$ \\
\hline E. B.-Q. & 32.3 & 32.2 & 7.4 & 36.1 & 159.5 & 5.3 & 40.2 & 395.6 & 4.2 \\
\hline V.C. ${ }^{\sim}$ & 37.8 & 19.7 & 4.1 & 41.9 & 99.5 & 4.4 & 44.3 & 160.4 & 12.2 \\
\hline R. F. G. & 28.2 & 5.2 & 9.3 & 39.0 & 194.8 & 4.9 & 43.4 & 331.7 & 5.7 \\
\hline I. E. S. & 30.2 & 46.7 & 7.2 & 32.9 & 142.5 & 5.8 & 38.6 & 379.4 & 5.9 \\
\hline B. U. & 33.7 & 49.7 & 8.1 & 38.2 & 272.2 & 4.3 & 46.3 & 898.7 & 1.1 \\
\hline J. V. W. & 30.3 & 27.7 & 6.9 & 36.8 & 217.2 & 2.6 & 41.2 & 554.8 & 2.2 \\
\hline Mean & 32.1 & 30.2 & 7.2 & 37.5 & 181.0 & 4.6 & 42.3 & 453.4 & 5.2 \\
\hline SEM & 1.4 & 6.8 & 0.7 & 1.2 & 24.8 & 0.5 & 1.2 & 103.0 & 1.6 \\
\hline$P^{*}$ & $<0.01$ & $<0.01$ & $<0.05$ & - & - & - & $<0.01$ & $<0.05$ & NS \\
\hline
\end{tabular}

* Values refer to difference from normocapnia. 

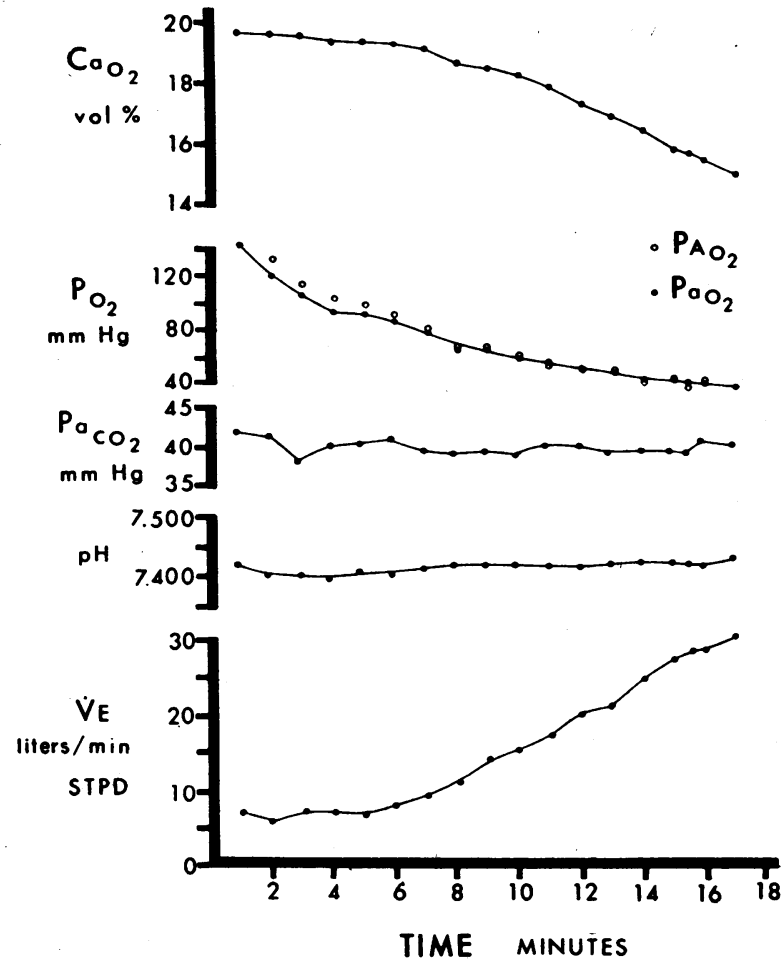

Figure 7 Serial values for $\mathrm{CaO}_{2}, \mathrm{PAO}_{2}, \mathrm{PaCO}_{2} \mathrm{pH}_{2}$ and VE collected over $17 \mathrm{~min}$ in a typical subject ( $R$. McG.) during progressive, isocapnic hypoxia (see Table III).

tion values for each minute were viewed in relation to the oxygen content of simultaneous arterial blood samples in each subject. In contrast to the curvilinear

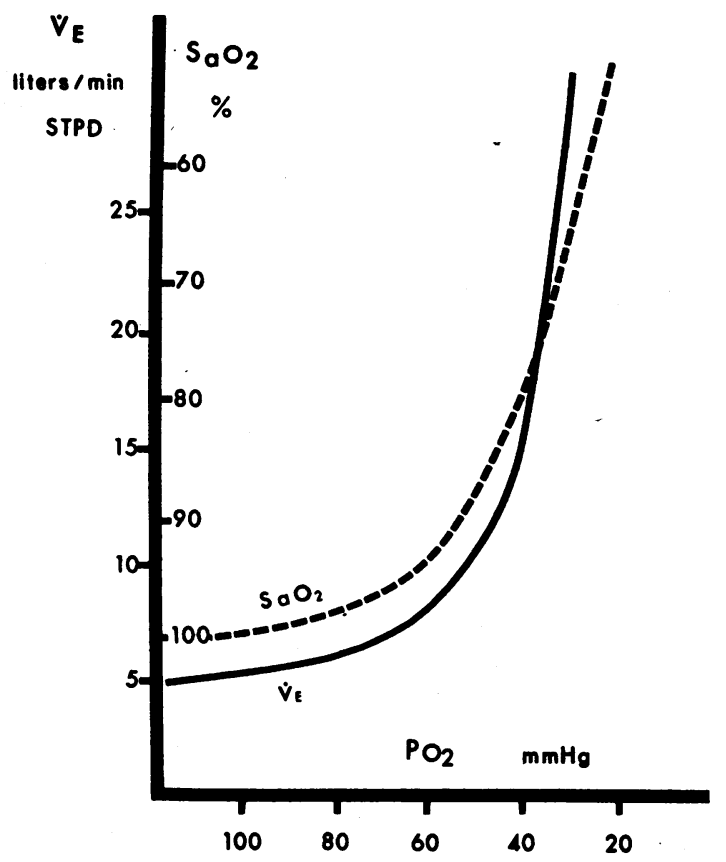

FIGURE 9 Minute ventilation-alveolar oxygen tension curve plotted in relation to an inverted oxygen-hemoglobin dissociation curve on common $\mathrm{P}_{\mathrm{O}_{2}}$ axis. Similarity between these curves in terms of similarity of oxygen tension range over which the respective inflection zones occur is evident.

relationship between oxygen tension and ventilation, oxygen content was related to ventilation in an essentially linear fashion (see Fig. 8). Regression lines were determined by least squares method.

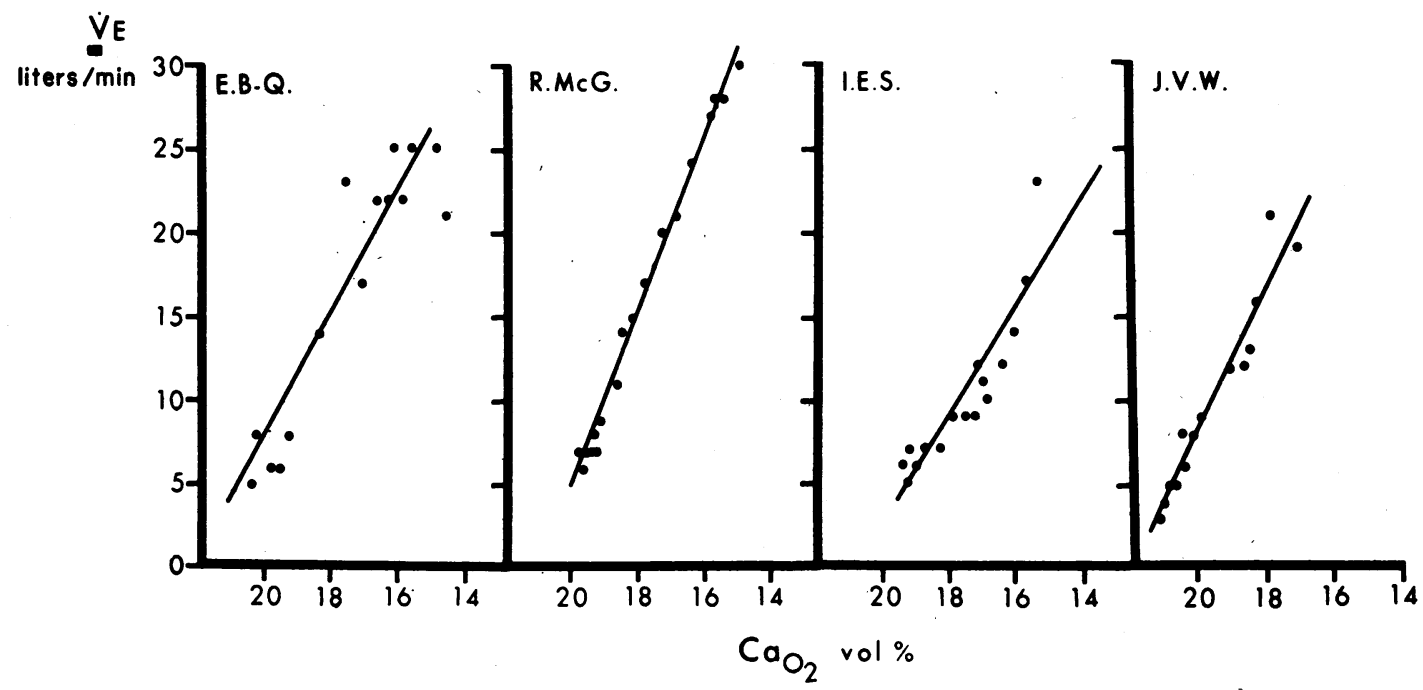

FIGURE 8 Linear relationship between minute ventilation and arterial oxygen content during progressive isocapnic hypoxia in four normal subjects. 
TABLE III

Results of Arterial Blood Studies during Progressive Isocapnic Hypoxia in Four Subjects

\begin{tabular}{|c|c|c|c|c|c|c|c|c|}
\hline & Time & $\mathrm{CaO}_{2}$ & $\mathbf{P A O}_{2}$ & $\mathrm{PaO}_{2}$ & $\mathrm{PACO}_{2}$ & $\mathrm{PaCO}_{2}$ & $\mathrm{pH}_{\mathbf{a}}$ & VE \\
\hline & $\min$ & vols \% & $m m \mathrm{Hg}$ & $m m \cdot H g$ & $m m \mathrm{Hg}$ & $m m \mathrm{Hg}$ & & liters/min \\
\hline \multirow[t]{18}{*}{ E. B.-Q. } & 1 & 19.81 & 124.0 & 120 & 35.0 & 36.0 & 7.415 & 6 \\
\hline & 2 & - & 116.0 & 112 & 35.6 & 36.5 & 7.410 & 4 \\
\hline & 3 & 20.46 & 97.5 & 73.5 & 35.6 & 35.5 & 7.405 & 5 \\
\hline & 4 & 20.33 & 91.9 & 89 & 34.4 & 35.5 & 7.400 & 7 \\
\hline & 5 & 19.61 & 83.1 & 80.5 & 33.8 & 35.0 & 7.415 & 6 \\
\hline & 6 & - & 76.9 & 78 & 34.4 & 34.5 & 7.410 & 9 \\
\hline & 7 & 19.32 & 68.8 & 69 & 34.4 & 35.5 & 7.415 & 11 \\
\hline & 8 & - & 60.6 & 63 & 34.4 & 35.0 & 7.395 & 11 \\
\hline & 9 & 18.38 & 53.8 & 54 & 32.5 & 32.0 & 7.415 & 16 \\
\hline & 10 & 17.10 & 48.1 & 49 & 33.1 & 31.5 & 7.430 & 17 \\
\hline & 11 & 17.61 & 44.4 & 47.5 & 33.1 & 33.0 & 7.430 & 23 \\
\hline & 12 & 16.62 & 41.9 & 42 & 34.4 & 33.0 & 7.430 & 23 \\
\hline & 13 & 15.89 & 41.9 & 42 & 34.4 & 32.5 & 7.425 & 23 \\
\hline & 14 & 16.11 & 40.0 & 41 & 33.8 & 36.0 & 7.425 & 25 \\
\hline & 15 & 14.93 & 40.6 & 40 & 34.4 & 32.0 & 7.420 & 23 \\
\hline & 16 & 16.38 & 40.0 & 40 & 33.1 & 35.0 & 7.425 & 23 \\
\hline & 17 & 15.64 & 37.5 & 38.5 & 35.6 & 34.0 & 7.430 & 25 \\
\hline & 17.5 & 14.58 & 38.8 & 36 & 34.4 & 32.5 & 7.430 & 23 \\
\hline \multirow[t]{18}{*}{ R. McG. } & 1 & 19.82 & & 131.0 & 38.4 & 42.0 & 7.420 & 7 \\
\hline & 2 & 19.70 & 120.3 & 111.0 & 38.4 & 41.5 & 7.405 & 6 \\
\hline & 3 & 19.60 & 105.2 & 100.0 & 37.8 & 38.0 & 7.405 & 7 \\
\hline & 4 & 19.44 & 97.0 & 88.0 & 37.8 & 40.0 & 7.400 & 7 \\
\hline & 5 & 19.42 & 94.5 & 87.0 & 36.5 & 40.0 & 7.410 & 7 \\
\hline & 6 & 19.36 & 86.3 & 83.0 & 37.8 & 41.0 & 7.410 & 8 \\
\hline & 7 & 19.18 & 76.9 & 75.5 & 37.2 & 39.0 & 7.415 & 9 \\
\hline & 8 & 18.65 & 66.8 & 64.0 & 37.8 & 39.0 & 7.420 & 11 \\
\hline & 9 & 18.53 & 63.0 & 62.5 & 38.4 & 39.0 & 7.420 & 14 \\
\hline & 10 & 18.25 & 57.3 & 58.5 & 37.8 & 38.5 & 7.420 & 15 \\
\hline & 11 & 17.85 & 52.9 & 54.5 & 37.8 & 40.0 & 7.420 & 17 \\
\hline & 12 & 17.29 & 49.8 & 50.0 & 38.4 & 39.5 & 7.420 & 20 \\
\hline & 13 & 16.90 & 46.6 & 47.5 & 37.2 & 38.5 & 7.425 & 21 \\
\hline & 14 & 16.38 & 43.5 & 44.5 & 37.2 & 39.0 & 7.430 & 24 \\
\hline & 15 & 15.78 & 42.2 & 42.0 & 37.2 & 39.0 & 7.430 & 27 \\
\hline & 15.5 & 15.68 & 41.6 & 41.5 & 36.5 & 38.5 & 7.430 & 28 \\
\hline & 16 & 15.38 & 39.7 & 40.5 & 37.8 & 40.5 & 7.425 & 28 \\
\hline & 17 & 14.97 & 37.8 & 38.5 & 37.2 & 40.0 & 7.435 & 30 \\
\hline \multirow[t]{14}{*}{ J. V. W. } & 1 & 21.10 & 131.3 & 127.0 & - & 39.0 & 7.420 & 4 \\
\hline & 2 & 20.81 & 125.6 & 115.0 & - & 39.0 & 7.420 & 3 \\
\hline & 3 & 20.80 & 114.3 & 101.5 & - & 36.0 & 7.420 & 5 \\
\hline & 4 & 20.73 & ' $\quad 99.2$ & 89.0 & - & 38.5 & 7.425 & 5 \\
\hline & 5 & 20.38 & 92.3 & 92.0 & - & 34.5 & 7.450 & 8 \\
\hline & 6 & 20.29 & 86.0 & 90.0 & - & 37.0 & 7.430 & 6 \\
\hline & 7 & 20.12 & 80.4 & 85.0 & - & 37.0 & 7.420 & 8 \\
\hline & 8 & 19.91 & 68.5 & 75.5 & - & 38.0 & 7.420 & 9 \\
\hline & 9 & 18.99 & 60.3 & 68.0 & - & 38.0 & 7.415 & 12 \\
\hline & 10 & 18.62 & 54.6 & 63.0 & - & 36.5 & 7.420 & 12 \\
\hline & 11 & 18.40 & 49.0 & 57.0 & - & 36.5 & 7.425 & 13 \\
\hline & 12 & 18.19 & 47.1 & 53.0 & - & 36.5 & 7.420 & 16 \\
\hline & 13 & 17.80 & 44.6 & 51.0 & - & 38.0 & 7.410 & 21 \\
\hline & 14 & 16.99 & 42.1 & 48.0 & - & 32.0 & 7.455 & 19 \\
\hline
\end{tabular}


TABLE III (continued)

\begin{tabular}{|c|c|c|c|c|c|c|c|c|}
\hline & Time & $\mathrm{CaO}_{2}$ & $\mathrm{PAO}_{2}$ & $\mathrm{PaO}_{2}$ & $\mathrm{PACO}_{2}$ & $\mathrm{PaCO}_{2}$ & $\mathrm{pH}_{\mathbf{2}}$ & VE \\
\hline & $\min$ & vols \% & $m m \mathrm{Hg}$ & $m m \mathrm{Hg}$ & $m m H_{g}$ & $m m H_{g}$ & & liters $/ \min$ \\
\hline \multirow[t]{16}{*}{ I. E. S. } & 1 & 19.45 & - & 141.0 & 31.6 & 29.5 & 7.395 & 6 \\
\hline & 2 & 19.24 & 124.0 & 135.0 & 32.4 & 33.0 & 7.400 & 5 \\
\hline & 3 & 19.21 & 103.0 & 103.0 & 31.0 & 33.0 & 7.410 & 7 \\
\hline & 4 & 19.00 & 87.4 & 90.0 & 31.0 & 31.5 & 7.420 & 6 \\
\hline & 5 & 18.70 & 80.6 & 77.0 & 31.6 & 32.5 & 7.420 & 7 \\
\hline & 6 & 18.30 & 73.8 & 74.0 & 31.0 & 32.0 & 7.420 & 7 \\
\hline & 7 & 17.91 & 65.7 & 65.5 & 31.0 & 32.0 & 7.430 & 9 \\
\hline & 8 & 17.50 & 62.6 & 61.5 & 31.6 & 30.0 & 7.430 & 9 \\
\hline & 9 & 17.25 & 62.0 & 60.5 & 32.9 & 32.0 & 7.430 & 9 \\
\hline & 10 & 17.12 & 58.3 & 59.5 & 32.4 & 33.0 & 7.420 & 12 \\
\hline & 11 & 17.03 & 52.7 & 54.5 & 31.6 & 32.0 & 7.435 & 11 \\
\hline & 12 & 16.87 & 49.6 & 51.5 & 31.6 & 32.0 & 7.440 & 10 \\
\hline & 13 & 16.45 & 46.5 & 48.5 & 32.4 & 31.0 & 7.445 & 12 \\
\hline & 14 & 16.12 & 42.8 & 45.5 & 31.0 & 31.0 & 7.450 & 14 \\
\hline & 15 & 15.68 & 40.3 & 42.0 & 31.0 & 30.0 & 7.445 & 17 \\
\hline & 16 & 15.40 & 39.4 & 39.0 & 30.1 & 30.5 & 7.445 & 23 \\
\hline
\end{tabular}

\section{DISCUSSION}

Measurement of the ventilatory response to isocapnic hypoxia in man was first described by Loeschke and Gertz (3). Subsequently, Cormack et al. (4) and Tenney et al. (5) both reported similar studies. All of these studies were prolonged, often required more than one sitting, and provided limited numbers of data points. The present study provides abundant data, but suffers from the potential disadvantage of being a non-steadystate method. For this reason the kinetics of ventilatory adjustment to hypoxia were carefully considered. It is certainly well established that ventilation responds rapidly to hypoxemia and the commonly employed single breath test of chemoreceptor function is based upon this knowledge (11). However, the lack of a continuous, rapid-responding oxygen analyzer capable of a high level of precision hampered attempts to define rigorously the time course of changes in ventilation in relation to alveolar oxygen tension. Availability of a fuel cell oxygen analyzer $(8,9)$ has solved this problem and studies using this instrument reveal that ventilation stabilizes at a steady-state value within approximately $18-23 \mathrm{sec}$ after attainment of a stable alveolar $\mathrm{P}_{\mathrm{o}_{2}}$ under isocapnic conditions. These figures were obtained using abrupt changes in inspired oxygen concentration and hence probably overestimate the extent of delay in ventilatory adjustment to gradual changes in inspired oxygen concentration. The prolonged periods often described for adjustment of ventilation to hypoxia are due mainly to the long period (1-2 min) required to lower alveolar $\mathrm{Po}_{2}$ following introduction of a hypoxic gas mixture. The true phase difference between changes in alveolar $\mathrm{P}_{\mathrm{o}_{2}}$ and changes in ventilation appears to be sufficiently small to justify the use of slowly progressive hypoxia as a test of ventilatory responsiveness. As already described the potential error introduced by this time delay is very small.

Throughout these studies much emphasis has been placed on values derived from continuous analysis of gas tensions of end-tidal air and questions could be raised concerning the extent to which these values truly reflect the chemistry of arterial blood. For this reason only normal subjects have been studied. It is generally assumed that end-tidal and arterial carbon dioxide tensions are identical in normal man and this was essentially true in the present study. In addition fuel cell values for end-tidal oxygen tension closely approximated arterial values especially at lower oxygen tensions. Because the end-tidal oxygen tensions reflect the absolute minimum tension registered with each breath these values are lower than those recorded with other end-tidal sampling techniques or calculated from the alveolar air equation. In fact these values may be slightly lower than mixed arterial blood and a slightly negative alveolar-arterial difference can on occasion be measured.

The subjects participating in this study were all longterm residents of moderate altitude $(1600 \mathrm{~m})$ and the question arises as to whether this influenced hypoxic ventilatory drive. Depression of the ventilatory response to hypoxia has been observed in persons native to high altitude (12-15), but none of the subjects in the present study was born at altitudes appreciably above sea level. Although Forster et al. (16) described accentuation of ventilatory response to hypoxia in lowlanders residing at high altitude for 45 days, the re- 
sponse in long-term residents was not vèry different from sea level residents. Similarly Sorenson and Severinghaus (17) found no difference in hypoxic ventilatory drive in sea level natives residing at high altitude and sea level natives living at sea level.

Differences in methods of calculation and expression of data made a direct comparison of hypoxic ventilatory responses between studies difficult. Some authors record a twofold increase in ventilation over control when alveolar $\mathrm{P}_{\mathrm{O}_{2}}$ is reduced from 150 to $40 \mathrm{~mm} \mathrm{Hg}$ $(4,7)$, whereas we find the increase to be approximately fourfold. Other workers express hypoxic sensitivity as the absolute difference in minute ventilation when alveolar $\mathrm{P}_{\mathrm{O}_{2}}$ is lowered from 150 to $40 \mathrm{~mm} \mathrm{Hg}$ expressed as liters per minute per square meter BSA $\left(\Delta \mathrm{V}_{40}\right)$. Values for $\Delta \mathrm{V}_{\text {40 }}$ in normal man at sea level have been reported as $9.6 \pm 2.4$ (SEM) liters/min per $\mathrm{m}^{2}$ (15), $10.4 \pm 1.5$ (16), and $33 \pm 8.0$ (18). From our data we have calculated the mean value of $17.0 \pm 1.5$ for this measurement which would appear to fall between the above values. Loeschke and Gertz (3) give no tabulated data but their figures relating ventilation to $\mathrm{PAO}_{2}$ appear similar to ours.

The equation employed for curve fitting represents a standard expression for a hyperbolic function and was originally used for this purpose by Lloyd et al. (7). It must be emphasized that we do not regard this equation as a model of ventilatory control but employ it simply as a means of reducing a continuous curve to a few parameters which can be more conveniently handled by traditional statistical methods. It is especially important to indicate that the extrapolated portions of these curves are artificial constructions and should not be regarded as predictive of physiological responses. Hence the fact that the ventilatory asymptote $\mathrm{VE}^{0}$ is not shifted by changes in $\mathrm{PAco}_{2}$ does not necessarily mean that alterations of $\mathrm{PAco}_{2}$ have no effect on ventilation at high $\mathrm{PAO}_{2}$ levels. The data of the present study give a clear picture of the interaction between hypoxic and hypercapnic stimuli and indicate that ventilatory responsiveness to hypoxia is greatly altered by acute changes in carbon dioxide tension. These findings are in close agreement with those of Loeschke and Gertz (3), Cormack et al. (4), and Tenney et al. (5). While we have not attempted in these studies to separate the effects of alterations of carbon dioxide tension per se from the effects of altered hydrogen ion concentration, the studies of Tenney et al. (5) suggest that hydrogen ion concentration is of primary importance in this regard.

It seems possible that the shape of the ventilation$\mathrm{PAO}_{2}$ curve is of some inherent significance. We have been impressed by the resemblance of these curves to the oxygen-hemoglobin dissociation curve in that both curves show an inflection over the same $\mathrm{P}_{o_{2}}$ range (Fig. 9). This implies that only oxygen tensions which are low enough to lower oxygen saturation stimulate ventilation. This in turn suggests that ventilation might be a linear function of arterial oxygen saturation or oxygen content. The results of the arterial blood studies indicate that this is in fact the case. Other attempts to linearize these data, including the use of semilogarithmic plots, have been to no avail. In our experience the oxygen-hemoglobin dissociation relationship has shown unique capability in this regard. A similar relationship has been found between discharge frequency of the carotid body and arterial oxygenation. Von Euler, Liljestrand, and Zotterman (19) showed that the rate of carotid body discharge is a linear function of arterial oxygen saturation while Hornbein, Griffo, and Roos (20) demonstrated that discharge frequency and arterial oxygen tension were related in a curvilinear fashion which resembles the form of our ventilationoxygen tension curves. Indeed Comroe, Forster, Dubois, Briscoe, and Carlsen (21) have suggested that the oxygen tension threshold for ventilation is very near the $\mathrm{Po}_{2}$ which marks the beginning of the steep slope portion of the oxygen-hemoglobin dissociation curve.

We have previously reported studies in which a relationship was found between arterial oxygen tension and red cell mass in chronically hypoxic normal man which also resembled the oxygen-hemoglobin dissociation curve (22). In these subjects red cell mass was related in curvilinear fashion to $\mathrm{Pa}_{2}$ such that increases in red cell mass were found only in those subjects in whom $\mathrm{Pa}_{2}$ was low enough to depress oxygen saturation. The relationship between red cell mass and oxygen saturation was linear. It was concluded that blood oxygen content, a major determinant of circulatory oxygen delivery and thus of tissue oxygen tension, played a major role in regulation of erythropoiesis. The notion that erythropoiesis is controlled by the level of tissue oxygenation is generally accepted (23-25). It would appear that the ventilatory response to hypoxia might be controlled in similar fashion, but there are several potential objections to this concept. First, it is thought that blood flow to the carotid body is immense relative to tissue mass and that the oxygen requirements of the chemoreceptor can virtually be met by dissolved oxygen alone (26). If this is true it would seem unlikely that the carotid body could sense changes in total oxygen delivered. However, the true effective tissue blood flow in the carotid body has not to our knowledge ever been determined. In addition activation of the sympathetic nervous system which occurs during hypoxia may greatly reduce carotid body flow during hypoxia (26). Secondly, there is general agreement that administration of carbon monoxide which preserves normal arterial oxygen tension but lowers oxygen content fails to stimulate ventilation (27-29). This has been strong evidence in support of the notion that the carotid body senses arterial oxygen tension rather than content. On the other hand, 
Mills and Edwards (30) have recently shown that although perfusion of the carotid body with blood containing various concentrations of carboxyhemoglobin does not stimulate ventilation, a marked rise in carotid body efferent impulses results. These findings stand in striking contrast to those of Duke and Neil (31) who found no evidence of carotid body stimulation under similar circumstances. It is possible that the failure of carbon monoxide to stimulate ventilation may in fact be the result of interference with central integrative mechanisms. Contrary to an often quoted statement that this is unlikely (32) there is considerable evidence that carbon monoxide can substantially disrupt central nervous system function at relatively small concentrations (33-35). For these reasons there must be some reservation regarding the ultimate significance of the effects of carbon monoxide on ventilation. Recent studies from our laboratory indicate that in awake cattle augmentation of oxygen transport produced by transfusion-induced increases in hematocrit decreased the ventilatory response to hypoxia (36). Yet studies by Eisele, Pegg, and Severinghaus (37) in anesthetized dogs showed no diminution in hypoxic drive following production of polycythemia. Hence we believe the nature of ventilatory control during hypoxia is not yet clear and should remain the object of further investigation.

\section{ACKNOWLEDGMENTS}

We wish to express our gratitude to Mr. George Fayette who performed the blood gas analyses and Mrs. Sharon Snyder and Mrs. Eva Toyos for the Van Slyke analyses required by this study.

Dr. Weil is the recepient of an established investigatorship of the Colorado Heart Association and Dr. ByrneQuinn is the recipient of a Wellcome Research Travel Grant and a fellowship from the Colorado Heart Association. This work supported in part by U. S. Army Contract No. DA49-193-MD-2227, Research and Training Grant RT-10 from the Social and Rehabilitation Service Section Department of Health Education and Welfare, Research Grant No. HE-03191 from the U. S. Public Health Service, and by a research grant from the American Thoracic Society.

\section{REFERENCES}

1. Altman, P. L., and D. S. Dittmer. 1966. Environmental Biology. Fed. Amer. Soc. Exp. Biol. Bethesda. 368.

2. Rahn, H. 1966. Development of gas exchange. Proc. Roy. Soc. Med. 59: 493.

3. Loeschcke, H. H., and K. H. Gertz. 1958. Einfluss des $\mathrm{O}_{2}$ -Druckes in Der Einatmungsluft auf die Atemtätigkeit des Menschen, gepruft unter Konstanthaltung des alveolaren $\mathrm{CO}_{2}$-Druckes. Pfluegers Arch. Gesamte Physiol. Menshen Tiere. $267: 460$.

4. Cormack, R. S., D. J. C. Cunningham, and J. B. L. Gee. 1957. The effect of carbon dioxide on the respiratory response to want of oxygen in man. Quart. J. Exp. Physiol. 42: 303.

5. Tenney, S. M., J. E. Remmers, and J. C. Mithoefer. 1963. Interaction of $\mathrm{CO}_{2}$ and hypoxic stimuli on ventilation at high altitude. Quart. J. Exp. Physiol. 48: 192.
6. Nielsen, M., and H. Smith. 1952. Studies on the regulation of respiration in acute hypoxia. Acta Physiol. Scand. 24: 293.

7. Lloyd, B. B., M. G. M. Jukes, and D. J. C. Cunningham. 1958. The relation between alveolar oxygen pressure and the respiratory response to carbon dioxide in man. Quart. J. Exp. Physiol. 43: 214.

8. Weil, J. V., I. E. Sodal, and R. P. Speck. 1967. A modified fuel cell for the analysis of oxygen concentration of gases. J. Appl. Physiol. 23: 419.

9. Sodal, I. E., R. R. Bowman, and G. F. Filley. 1968. A fast response oxygen analyzer with high accuracy for respiratory gas measurement. J. Appl. Physiol. 25: 181.

10. Burnette, W. A., and C. S. Roberts. 1967. NLLSQ-A Fortran IV Nonlinear least squares Fitting Program. Memorandum. Bell Telephone Laboratories.

11. Dejours, P. 1962. Chemoreflexes in breathing. Physiol. Rev. 42: 335.

12. Chiodi, H. 1957. Respiratory adaptation to chronic high altitude hypoxia. J. Appl. Physiol. 10: 81.

13. Severinghaus, J. W., C. R. Bainton, and A. Carcelen. 1966. Respiratory insensitivity to hypoxia in chronically hypoxic man. Resp. Physiol. 1: 308.

14. Milledge, J. S., and S. Lahiri. 1967. Respiratory control in lowlanders and Sherpa highlanders at altitude. Resp. Physiol. 2: 310.

15. Sorensen, S. C., and J. W. Severinghaus. 1968. Irreversible respiratory insensitivity to acute hypoxia in man born at high altitude. J. Appl. Physiol. 25: 217.

16. Forster, H. V., J. A. Dempsey, M. L. Birnbaum, W. G. Reddan, J. S. Thoden, R. F. Grover, and J. Rankin. 1969. Comparison of ventilatory responses to hypoxic and hypercapnic stimuli in altitude-sojourning lowlanders, lowlanders residing at altitude and native altitude residents. Fed. Proc. 28: 1274.

17. Sorensen, S. C., and J. W. Severinghaus. 1968. Respiratory sensitivity to acute hypoxia in man born at sea level residing at high altitude. J. Appl. Physiol. 25: 211.

18. Kronenberg, R., F. N. Hamilton, R. Gabel, R. Hickey, D. J. C. Read, and J. Severinghaus. 1969. Quantitation of respiratory response to hypoxia in man. Clin. Res. $17: 416$.

19. von Euler, U. S., G. Liljestrand, and Y. Zotterman. 1939. The excitation mechanism of the chemoreceptors of the carotid body. Scand. Arch. Physiol. 83: 132.

20. Hornbein, T. F., Z. J. Griffo, and A. Roos. 1961. Quantitation of chemoreceptor activity: interrelation of hypoxia and hypercapnia. J. Neurophysiol. 24: 561.

21. Comroe, J. H., Jr., R. E. Forster II, A. B. Dubois, W. A. Briscoe, and E. Carlsen. 1962. The Lung. Year Book Medical Publishers. Chicago. 2nd edition.

22. Weil, J. V., G. Jamieson, D. W. Brown, and R. F. Grover. 1968. The red cell mass-arterial oxygen relationship in normal man. J. Clin. Invest. 47: 1627.

23. Fried, W. L., L. F. Plzak, L. O. Jacobson, and E. Goldwasser. 1957. Studies on erythropoiesis. III. Factors controlling erythropoietin production. Proc. Soc. Exp. Biol. Med. 94 : 237.

24. Stohlman, F., Jr. 1962. Erythropoiesis. N. Engl. J. Med. $267: 342$.

25. Charache, S., D. J. Weatherall, and J. B. Clegg. 1966. Polycythemia associated with a hemoglobinopathy. $J$. Clin. Invest. 45 : 813.

26. Daly, M. De B., C. J. Lambertsen, and A. Schweitzer. 1954. Observations on the volume of blood flow and oxygen utilization of the carotid body in the cat. J. Physiol. 125 : 67.

Hypoxic Ventilatory Drive in Normal Man

1071 
27. Comroe, J. H., Jr., and C. F. Schmidt. 1938. The part played by reflexes from the carotid body in the chemical regulation of respiration in the dog. Amer. J. Physiol. $121: 75$.

28. Chiodi, H., D. B. Dill, F. Consolazio, and S. M. Horvath. 1941. Respiratory and circulatory responses to acute carbon monoxide poisoning. Amer. J. Physiol. 134: 683.

29. Klausen, K., B. Rasmussen, H. Gjellerod, H. Madsen, and E. Petersen. 1968. Circulation, metabolism and ventilation during prolonged exposure to carbon monoxide and to high altitude. Scand. J. Clin. Lab. Med. 22 (Suppl. $103)$ : 26.

30. Mills, E., and M. W. Edwards, Jr. 1968. Stimulation of aortic and carotid chemoreceptors during carbon monoxide inhalation. J. Appl. Physiol. 25: 494.

31. Duke, H. N., J. A. Green, and E. Neil. 1952. Carotid chemoreceptor impulse activity during inhalation of carbon monoxide mixtures. J. Physiol. 118: 520.
32. Root, W. S. 1965. Carbon monoxide. In Handbook of Physiology. W. O. Fenn and H. Rahn, editors. The American Physiology Society, Washington. 2: 1087.

33. Lilienthal, J. L., Jr., and C. H. Fugitt. 1946. The effect of low concentrations of carboxyhemoglobin on the "altitude tolerance" of man. Amer. J. Physiol. 145: 359.

34. Schulte, J. H. 1963. Effects of mild carbon monoxide intoxication. Arch. Environ. Health 7: 524.

35. Beard, R. R., and G. A. Wertheim. 1967. Behavioral impairment associated with small doses of carbon monoxide. Amer. J. Public Health Nat. Health. 57: 2012.

36. Bisgard, G. E., H. G. Alvarez, and R. F. Grover. 1969. Decreased ventilatory response to hypoxia during acute polycythemia in the calf. Resp. Physiol. 7: 369.

37. Eisele, J. H., J. Pegg, and J. W. Severinghaus. 1969. Ventilatory response to hypoxia in acutely polycythemic dogs. J. Appl. Physiol. 26: 757. 